\title{
Suppression of Tumor Angiogenesis by Nonsteroidal Anti-Inflammatory Drugs: A New Function for Old Drugs
}

\author{
Curzio Rüegg and Olivier Dormond \\ Laboratory of the Centre Pluridisciplinaire d'Oncologie (CePO), University of Lausanne \\ Medical School, Swiss Institute for Experimental Cancer Research (ISREC), 155 \\ Chemin des Boveresses, $\mathrm{CH}$-1066 Epalinges, Switzerland
}

Received November 5, 2001; Accepted November 14, 2001; Published December 1, 2001

\begin{abstract}
KEY WORDS: cancer, integrins, angiogenesis, NSAIDs, endothelial cells, Rho-family GTPases
\end{abstract}

DOMAINS: cardiovascular biology, signalling, cancer, pathology, extracellular matrix, metastasis, biochemistry, pharmacology, cell biology, cell and tissue culture, experimental medicine, clinical trials

There is solid epidemiological evidence demonstrating that the regular use of nonsteroidal antiinflammatory drugs (NSAIDs) reduces the risk of developing colorectal cancer, and to a lesser extent gastric and esophageal cancers[1]. Importantly, NSAIDs suppress colon polyp formation and progression in patients diagnosed with familial adenomatous polyposis coli (APC)[2]. In many animal studies, NSAIDs have been shown to prevent tumor formation and slow tumor progression, thus confirming and extending the clinical observations[3,4,5]. Recent findings have demonstrated that NSAIDs inhibit angiogenesis, suggesting that the tumor suppressive activity of these drugs may be due, at least in part, to their ability to inhibit tumor angiogenesis[6]. The study of the mechanism by which NSAIDs suppress tumor angiogenesis, is matter of intense research.

In a recent paper published in Nature Medicine[7], we reported that inhibition of COX-2 by the nonselective cyclooxygenase (COX) inhibitor indomethacin or the selective COX-2 antagonist NS-398 blocked FGF-2-induced angiogenesis in mice. In vitro, indomethacin and NS398 suppressed endothelial cell spreading and migration mediated by integrin $\alpha \mathrm{V} \beta 3$, an adhesion receptor critically involved in promoting tumor angiogenesis[8]. This effect was associated with the suppression of $\alpha \mathrm{V} \beta 3$-dependent activation of Cdc42 and Rac, two members of the Rho family of GTPases that regulate cytoskeletal organization and cell migration. Expression of a constitutive active form of Rac prevented NS-398-induced suppression of endothelial cell spreading and migration in vitro and reversed the inhibition of angiogenesis caused by NS-398 in vivo. Taken together, these results implicate that inhibition of $\alpha \mathrm{V} \beta 3$-mediated Rac activation is an important mechanism by which NSAIDs suppress endothelial cell migration and angiogenesis.

COX-1 and COX-2 are the rate-limiting enzymes in the conversion of arachidonic acid into prostaglandins (e.g., $\mathrm{PGE}_{2}, \mathrm{PGF}_{2 \alpha}, \mathrm{PGD}_{2}, \mathrm{PGI}_{2}$ ) and thromboxans[9]. COX-1 is constitutively expressed in most tissues and plays an important role in tissue homeostasis. In contrast, COX-2 is absent from most normal tissues and its expression is up-regulated in inflammation[10] and in many cancers, including colon, breast, prostate, and skin[11]. 


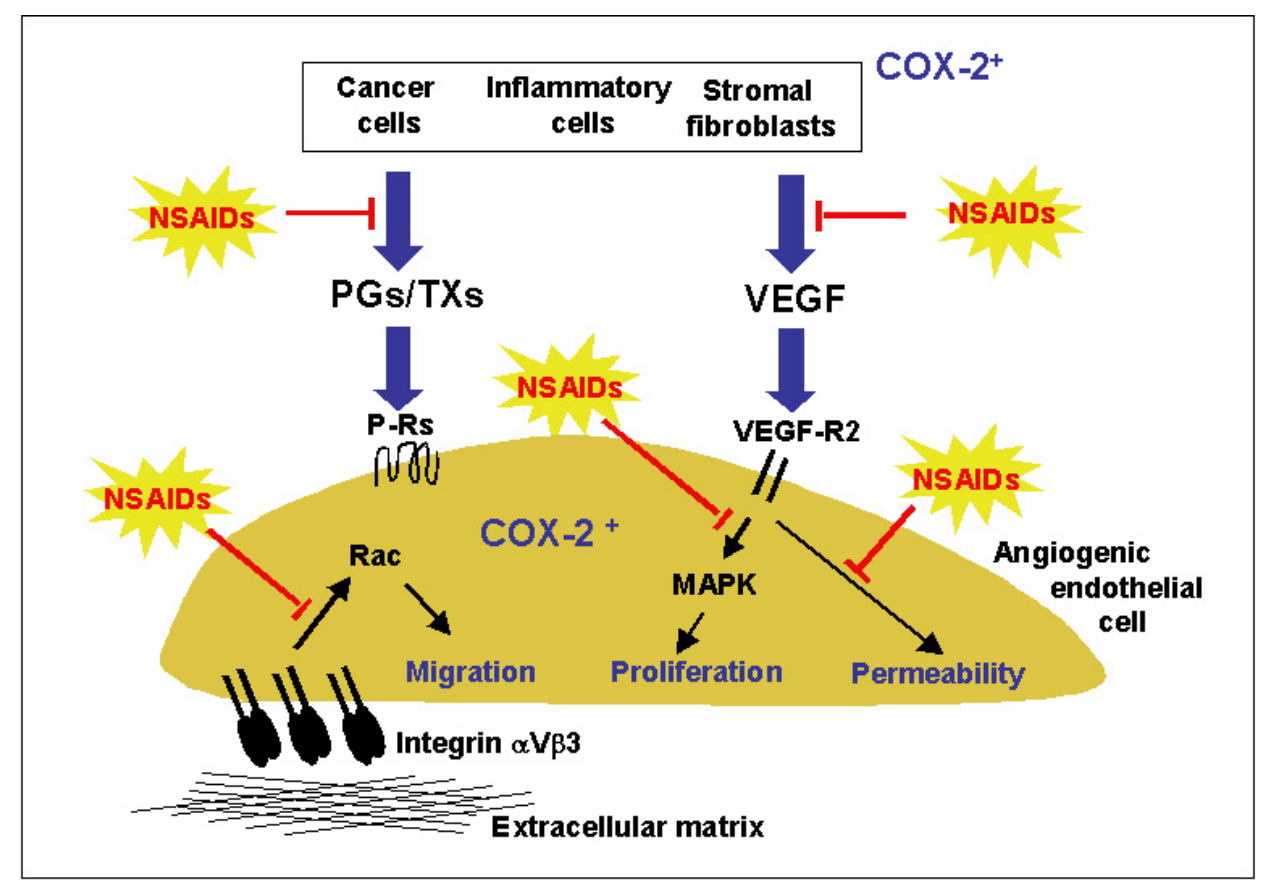

FIGURE 1. Schematic representation of the effects of NSAIDs on angiogenic endothelial cells. Cancer cells, stromal fibroblasts, infiltrating inflammatory cells and angiogenic endothelial cells up-regulate COX-2 resulting in increased production of prostaglandins and thromboxane (PG/TX). PG/TX bind to prostanoid receptors and regulate signaling from the VEGF receptor 2 (VEGF-R2) and integrin $\alpha \mathrm{V} \beta 3$. NSAIDs inhibit PG/TX and VEGF production, suppress endothelial cell proliferation and vascular permeability in response to VEGF and inhibit $\alpha \mathrm{V} \beta 3$ integrin-dependent Rac activation and endothelial cell migration.

Within the tumor microenvironment, COX-2 is expressed by cancer cells, stromal fibroblasts, tumor infiltrating inflammatory cells, and angiogenic endothelial cells[11]. Consistent with a role of COX-2 in tumor progression, inhibition of COX-2 by NSAIDs reduced the growth of many experimental tumors. For example, topical application of diclofenac, a nonselective NSAID, retarded Colon-26 tumor growth in mice and this effect was associated with suppressed tumor angiogenesis[12]. Subsequently it was shown that COX-2 antagonists inhibited growth factorinduced angiogenesis. In a rat model of angiogenesis the COX-2 inhibitor celecoxib, blocked corneal blood vessel formation while SC-560, a specific COX-1 inhibitor had no effect[11].

Previous reports demonstrated that COX-2 regulates the expression of Vascular Endothelial Growth Factor (VEGF) as well as the biological response of endothelial cell response to VEGF. Mice lacking the COX-2 gene had deficient production of VEGF by fibroblasts and treatment of wild-type fibroblasts with a selective COX-2 inhibitor suppressed VEGF production[13]. Overexpression of COX-2 in colon cancer cells induced expression of VEGF and other angiogenic factors and this effect was inhibited by the COX-2-specific antagonist NS398[6]. Consistent with these findings, prostaglandins enhanced VEGF production in many different cells[14]. COX-2 is also involved in the regulation of VEGF-induced vascular permeability and endothelial cell proliferation. Indomethacin blocked increased vascular permeability in response to VEGF while administration of prostaglandin $\mathrm{I}_{2}$ increased vascular permeability[15]. Inhibition of COX-2 by NS-398 prevented VEGF-mediated MAPK activation and endothelial cell proliferation[16]. Taken together, these reports demonstrate that NSAIDs suppress tumor angiogenesis by inhibiting at least three different events of the angiogenic cascade: down-regulation of the production of angiogenic factors, inhibition of the endothelial cell response to VEGF, and suppression of integrin $\alpha \mathrm{V} \beta 3$-dependent endothelial cell migration.

Where do we go from here? First, we should further investigate the molecular effects of NSAIDs on endothelial cells. For example, we know little about the intracellular events 
responsible for the inhibition of VEGF-induced MAPK activation and the suppression of $\alpha \mathrm{V} \beta 3$ mediated cdc42 and Rac activation. Second, we should evaluate the potential therapeutic effects of this drug class as antiangiogenic agents in human cancer. Choosing the right patients, therapy regimens, and endpoints will be essential for the success of these trials.

Choice of the type of cancer and stage. Colorectal cancer is the prime choice, since we already know that NSAIDs protect against this cancer. It may also be important to include patients at different tumor stages, for example disease-free patients at high risk for recurrence (e.g., stage III colon cancer) and patients with advanced colon cancer (e.g., liver metastasis). Indeed we know from preclinical studies that antiangiogenic drugs given at different stages of tumor progression produce distinct efficacy profiles[17].

Therapy combination and schedule. Since it is unlikely that NSAIDs will have any therapeutic effects when given alone, they should be tested in combination with chemotherapy or radiotherapy. This concept is supported by experimental data[18,19]. In addition, it will be important to compare the effects of synchrone vs. alternate administration in relationship to chemotherapy or radiotherapy.

Evaluation of NSAIDs anticancer effects. This is a critical point common to all clinical trials involving antiangiogenic drugs. Since the antitumor effect of antiangiogenic drugs is indirect, it will be important to assess the effects on the tumor vasculature independently of the overall antitumor response. Imaging of the tumor vasculature by Computer Assisted Tomography (CAT scan), Magnetic Resonance Imaging (MRI), Positron Emission Tomography (PET), and Power-Doppler[20-22] allows to detect effects on tumor vessels. These techniques, however, have some limitations and the identification of sensitive and reliable biological and surrogate markers of angiogenesis will be instrumental to the clinical evaluation of antiangiogenic drugs, including NSAIDs.

\section{REFERENCES}

1. Thun, M.J., Namboodiri, M.M., and Heath, C.W., Jr. (1991) Aspirin use and reduced risk of fatal colon cancer. N. Engl. J. Med. 325, 1593-1596.

2. Giardiello, F.M., Hamilton, S.R., Krush, A.J., Piantadosi, S., Hylind, L.M., Celano, P., Booker, S.V., Robinson, C.R., and Offerhaus, G.J. (1993) Treatment of colonic and rectal adenomas with sulindac in familial adenomatous polyposis. N. Engl. J. Med. 328, 1313-1316.

3. Williams, C.S., Mann, M., and DuBois, R.N. (1999) The role of cyclooxygenases in inflammation, cancer, and development. Oncogene 18, 7908-7916.

4. $\quad$ Reddy, B.S., Hirose, Y., Lubet, R., Steele, V., Kelloff, G., Paulson, S., Seibert, K., and Rao, C.V. (2000) Chemoprevention of colon cancer by specific cyclooxygenase-2 inhibitor, celecoxib, administered during different stages of carcinogenesis. Cancer Res. 60, 293-297.

5. $\quad$ Oshima, M., Murai, N., Kargman, S., Arguello, M., Luk, P., Kwong, E., Taketo, M.M., and Evans, J.F. (2001) Chemoprevention of intestinal polyposis in the Apcdelta716 mouse by rofecxib, a specific cyclooxygenase-2 inhibitor. Cancer Res. 61, 1733-1740.

6. Tsujii, M., Kawano, S., Tsuji, S., Sawaoka, H., Hori, M., and DuBois, R.N. (1998) Cyclooxygenase regulates angiogenesis induced by colon cancer cells. Cell 93, 705-716.

7. Dormond, O., Foletti, A., Paroz, C., and Ruegg, C. (2001) NSAIDs inhibit alphaVbeta3 integrin-mediated and Cdc42/Rac-dependent endothelial-cell spreading, migration and angiogenesis. Nat. Med. 7, 1041-1047.

8. Brooks, P.C., Clark, R.A., and Cheresh, D.A. (1994) Requirement of vascular integrin alpha v beta 3 for angiogenesis. Science 264, 569-571.

9. $\quad$ Dubois, R.N., Abramson, S.B., Crofford, L., Gupta, R.A., Simon, L.S., Van De Putte, L.B., and Lipsky, P.E. (1998) Cyclooxygenase in biology and disease. FASEB J. 12, 1063-1073.

10. Coyne, D.W., Nickols, M., Bertrand, W., and Morrison, A.R. (1992) Regulation of mesangial cell cyclooxygenase synthesis by cytokines and glucocorticoids. Am. J. Physiol. 263, F97-102.

11. Masferrer, J.L., Leahy, K.M., Koki, A.T., Zweifel, B.S., Settle, S.L., Woerner, B.M., Edwards, D.A., Flickinger, A.G., Moore, R.J., and Seibert, K. (2000) Antiangiogenic and antitumor activities of cyclooxygenase-2 inhibitors. Cancer Res. 60, 1306-1311. 
12. Seed, M.P., Brown, J.R., Freemantle, C.N., Papworth, J.L., Colville-Nash, P.R., Willis, D., Somerville, K.W., Asculai, S., and Willoughby, D.A. (1997) The inhibition of colon-26 adenocarcinoma development and angiogenesis by topical diclofenac in $2.5 \%$ hyaluronan. Cancer Res. 57, 1625-1629.

13. Williams, C.S., Tsujii, M., Reese, J., Dey, S.K., and DuBois, R.N. (2000) Host cyclooxygenase-2 modulates carcinoma growth. J. Clin. Invest. 105, 1589-1594.

14. Ben-Av, P., Crofford, L.J., Wilder, R.L., and Hla, T. (1995) Induction of vascular endothelial growth factor expression in synovial fibroblasts by prostaglandin $\mathrm{E}$ and interleukin-1: a potential mechanism for inflammatory angiogenesis. FEBS Lett. 372, 83-87.

15. Murohara, T., Horowitz, J.R., Silver, M., Tsurumi, Y., Chen, D., Sullivan, A., and Isner, J.M. (1998) Vascular endothelial growth factor/vascular permeability factor enhances vascular permeability via nitric oxide and prostacyclin. Circulation 97, 99-107.

16. Jones, M.K., Wang, H., Peskar, B.M., Levin, E., Itani, R.M., Sarfeh, I.J., and Tarnawski, A.S. (1999) Inhibition of angiogenesis by nonsteroidal anti-inflammatory drugs: insight into mechanisms and implications for cancer growth and ulcer healing. Nat. Med. 5, 1418-1423.

17. Bergers, G., Javaherian, K., Lo, K.M., Folkman, J., and Hanahan, D. (1999) Effects of angiogenesis inhibitors on multistage carcinogenesis in mice. Science 284, 808-812.

18. Schiller, J.H. and Bittner, G. (1999) Potentiation of platinum antitumor effects in human lung tumor xenografts by the angiogenesis inhibitor squalamine: effects on tumor neovascularization. Clin. Cancer Res. 5, 4287-4294

19. Gorski, D.H., Mauceri, H.J., Salloum, R.M., Gately, S., Hellman, S., Beckett, M.A., Sukhatme, V.P., Soff, G.A., Kufe, D.W., and Weichselbaum, R.R. (1998) Potentiation of the antitumor effect of ionizing radiation by brief concomitant exposures to angiostatin. Cancer Res. 58, 5686-5689.

20. Ferrara, K.W., Merritt, C.R., Burns, P.N., Foster, F.S., Mattrey, R.F., and Wickline, S.A. (2000) Evaluation of tumor angiogenesis with US: imaging, Doppler, and contrast agents. Acad. Radiol. 7, 824-839.

21. Neeman, M., Provenzale, J.M., and Dewhirst, M.W. (2001) Magnetic resonance imaging applications in the evaluation of tumor angiogenesis. Semin. Radiat. Oncol. 11, 70-82.

22. Miles, K.A., Charnsangavej, C., Lee, F.T., Fishman, E.K., Horton, K., and Lee, T.Y. (2000) Application of CT in the investigation of angiogenesis in oncology. Acad. Radiol. 7, 840-850.

\section{This article should be referenced as follows:}

Rüegg, C. and Dormond, O. (2001) Suppression of tumor angiogenesis by nonsteroidal anti-inflammatory drugs: a new functin for old drugs. TheScientificWorld 1, 808-811. 


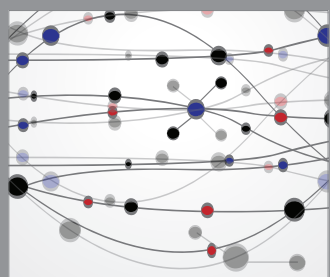

The Scientific World Journal
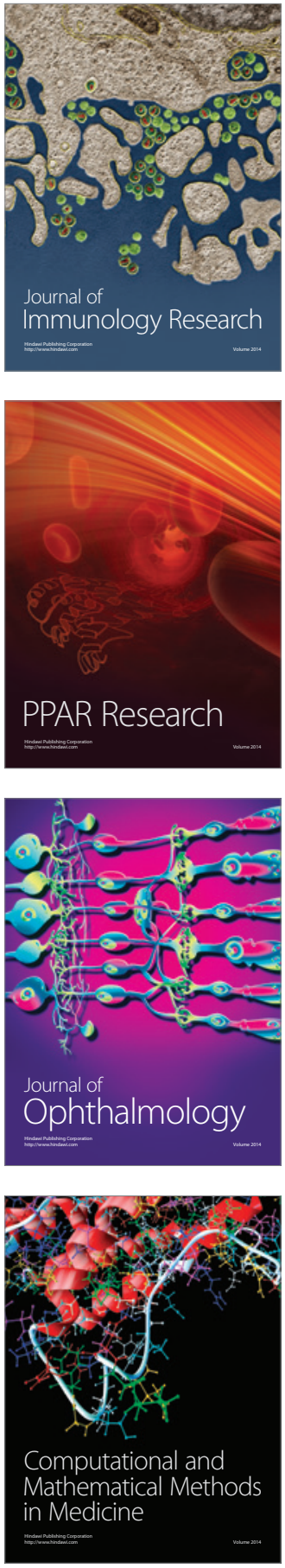

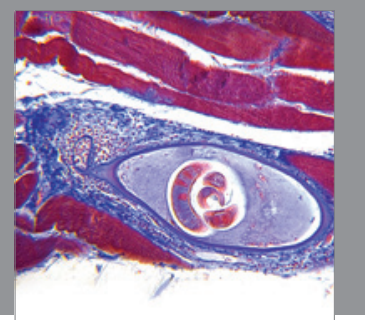

Gastroenterology

Research and Practice
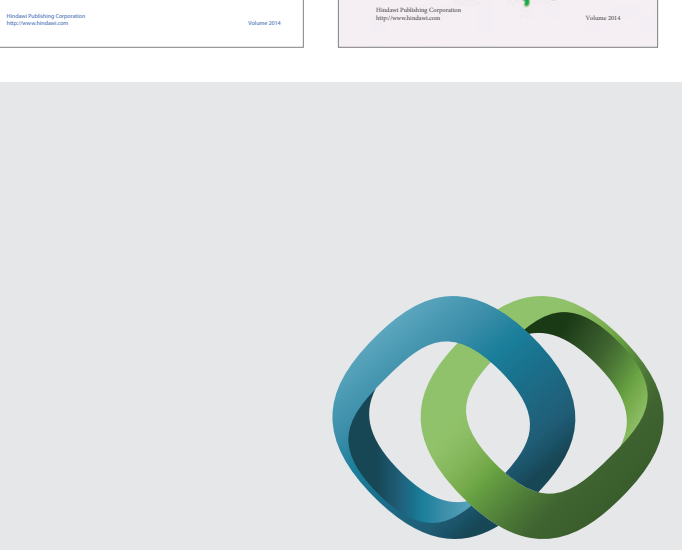

\section{Hindawi}

Submit your manuscripts at

http://www.hindawi.com
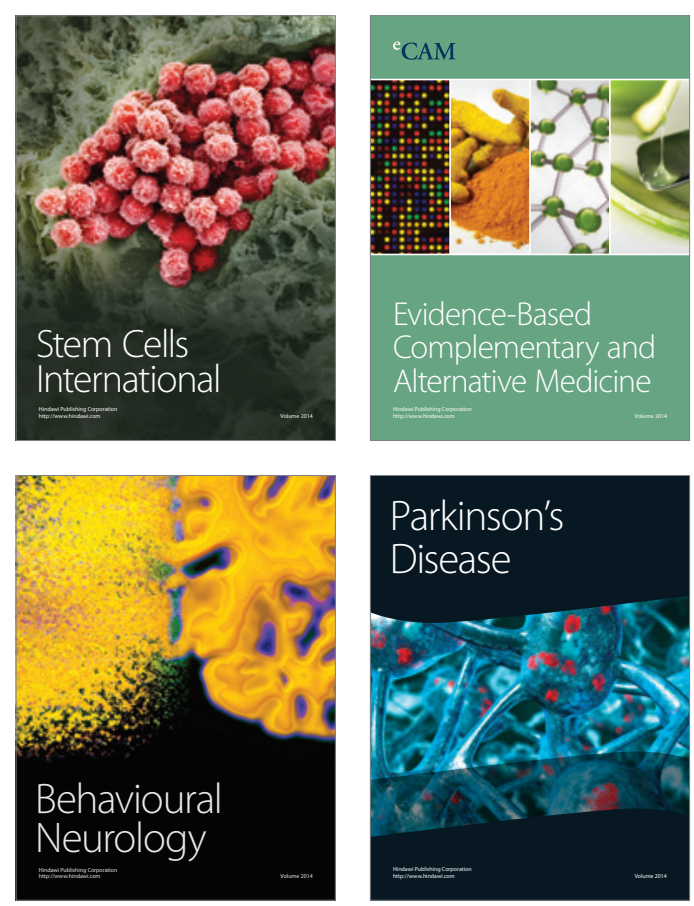

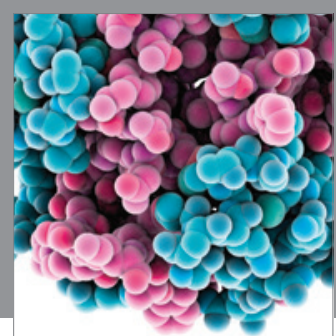

Journal of
Diabetes Research

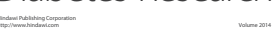

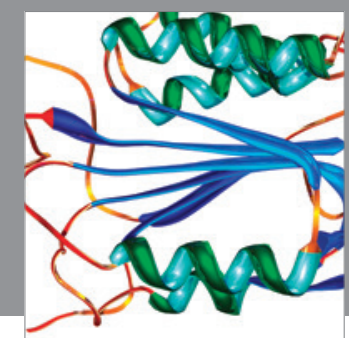

Disease Markers
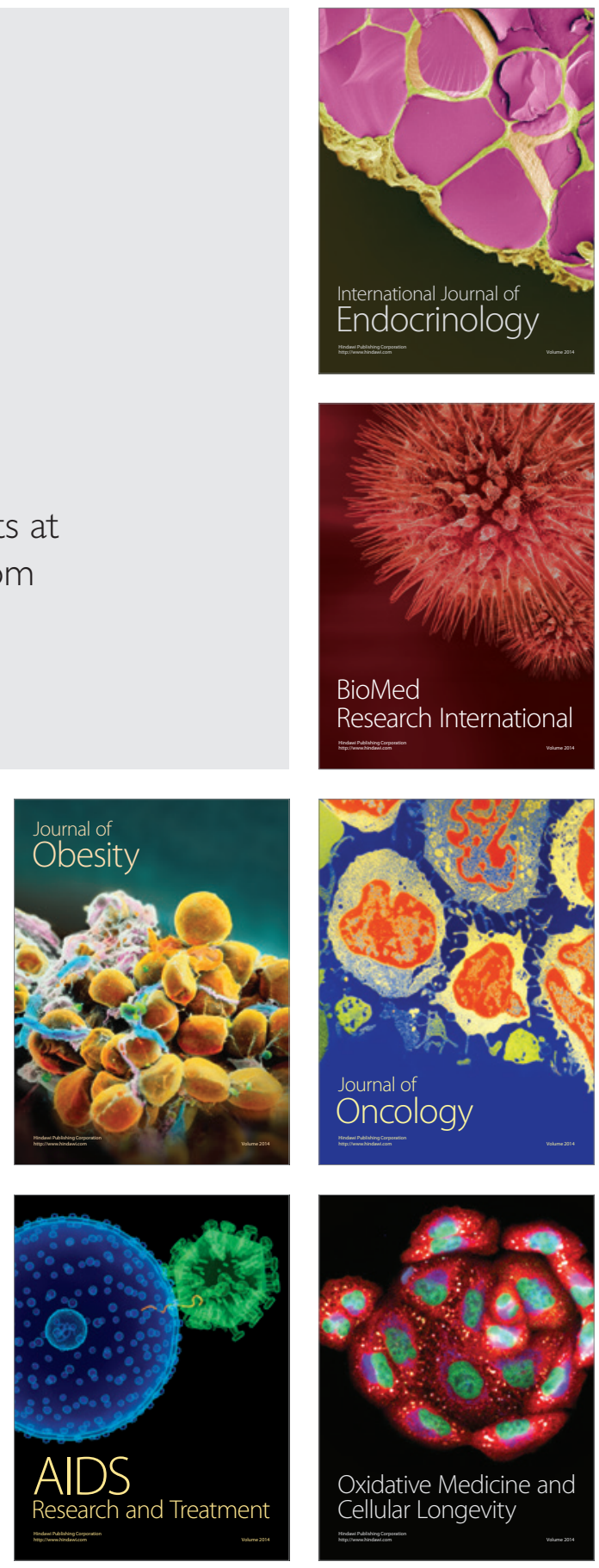